\title{
University Leadership of Professional Development Schools
}

\author{
Excelsior: Leadership in \\ Teaching and Learning \\ 2018, Vol. 11(1) 18-30 \\ (C) The Authors 2018 \\ CC-BY 4.0 International \\ Reprints and permissions: \\ surface.syr.edu/excelsior \\ https://doi.org/10.14305/jn.1 \\ 9440413.2018.11.1.02 \\ nyacte.org

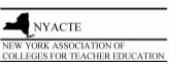

\section{Diane W. Gómez ${ }^{1}$ and Shelley B. Wepner ${ }^{1}$}

\begin{abstract}
This study investigated the roles and responsibilities of University-Based Administrators (UBAs) in relation to their oversight of Professional Development Schools (PDSs). UBAs refer to college administrators such as department chairs, program coordinators, directors, assistant deans, associate deans, and deans. The participants were 36 UBAs ranging from mid-level administrators to faculty chairpersons. They represented universities of various sizes and Carnegie classifications from across the United States. The UBAs responded through email or by telephone to nine semi-structured interview questions related to their PDS work. The majority of UBAs were tenure-track or clinical faculty, who spent less than $50 \%$ of their time on PDS work. Forty-six percent of the UBAs' Institutions of Higher Education (IHEs) partnered with between one to ten PDSs. The majority of the IHEs had been doing PDS work for 11-19 years. Findings revealed significant variation in UBA's roles and responsibilities. There is no standardized leadership title, set of responsibilities or qualifications, or structure for the oversight of PDS activities and networks. Three major administrative responsibilities related to PDS work emerged: personnel, programs, and documents. UBAs reported the greatest challenges were time, sustainability, and resources/support.
\end{abstract}

\section{Keywords}

University-Based Administrators (UBAs), Professional Development Schools (PDSs), leadership, administrative roles, partnerships

The establishment of cross-institutional cultures between P-12 and colleges and universities are essential for unifying the profession and contributing to the knowledge base about teaching and learning. P-12 education needs higher education to understand current instructional methodologies, assist teachers with professional development, provide instructional assistance to students, and learn how to best prepare a

\footnotetext{
${ }^{1}$ Manhattanville College

Corresponding Author:

Diane W. Gómez, School of Education, Manhattanville College, 2900 Purchase Street, Purchase, NY 10577.

Email: diane.gomez@mville.edu
} 
diverse student population for college, vocational, and societal success. Likewise, higher education needs P-12 education in order to prepare prospective teachers and leaders, assist faculty with their own professional development, and help with credibility and viability (Wepner, 2014a).

These cross-institutional partnerships require sustainable relationships between individuals and groups as they work together for a common cause. The depth and breadth of these relationships depend on factors such as accessibility to and availability of partners, leadership interest and capability, teacher buy-in, funding opportunities, and community support. There needs to be a shared commitment among partners and a willingness to work across institutional settings and cultures (Byrd \& McIntyre, 2011; Duffield \& Cates, 2008). A key factor for the success of any partnership--whether it is a school-university partnership that exists for a short time period to accomplish a specific task such as implementing a new literacy program or one that exists for long periods of time to address multiple pursuits in the form of a Professional Development School (PDS)--is both the school-based leadership and the university-based leadership.

While substantial research exists on the roles and responsibilities of school-based administrators (SBAs) in forming and sustaining PDSs (Bowen, 1995; Bowen \& Adkinson, 1996; Field, 2008; Tilford, 2010), the same cannot be said about the study of UBAs in forming and sustaining PDSs (Stroble \& Luka, 2011; Trachtman \& Levine, 1997). This paper addresses the leadership of UBAs-their roles, responsibilities, and challenges--in the context of PDSs.

\section{Literature on Partnerships and UBAs}

\section{Benefits of Partnerships}

Numerous reasons exist for pursuing school-university partnerships. For example, partnerships can raise the level of teacher expectation and student work; increase the student-teacher ratio; expose teachers to new and enhanced methodology; increase teacher leadership; offer innovative and cutting-edge ideas that teachers can use and apply; stimulate collaborative inquiry about practice; cultivate students' improved attitude toward learning; offer new and exciting dialogues about teaching and learning; infuse new blood into the building; and help with teacher renewal (Gilles, Wilson, \& Elias, 2009; Hamel \& Ryken, 2010; Wepner, 2014b,). PDSs, especially, have been shown to promote teachers' self-reflection about their instructional and assessment practices; improve student achievement; and provide teacher candidates with the knowledge, skills, and dispositions to enter and remain in the teaching profession (Byrd \& McIntryre, 2011; Castle, Rockwood, \& Tortora, 2008; Ferrara \& Gómez, 2014; McBee \& Moss, 2002; Stroble \& Luka, 2011; Teitel, 1996, 1997,1998,1999, 2003; Walker, Sorensen, Smaldino \& Downey, 2008; Walker, Zeek, Foote, \& Naizer, 2008).

\section{Challenges of Partnerships}

There also are challenges to forming partnerships that need to be acknowledged and addressed by UBAs. Such challenges include: 1) a paradigm shift, 2) institutional culture clashes, 3) conflicting expectations, 4) communication, and 5) flow of activities from university to P-12 schools (Moreno, 2005; Tomanek, 2005; Wepner et al., 2008). 
Paradigm shift. Developing a PDS involves a paradigm shift about who is in charge and what is expected, especially as two different cultures are brought together. UBAs need to partner with SBAs to bring together four different types of groups-classroom teachers, university faculty, P-12 students, and university students-to engage in new types of learning experiences and involve teacher candidates in the classroom to provide assistance to P-12 learners (Epstein \& Sanders, 2006; Wepner, 2011).

Institutional culture clashes. An institutional culture clash speaks to a set of differing principles by which different groups operate; for example, how one's day is scheduled, how one is compensated for one's work, how one is evaluated for job performance, how one's work environment should be managed, and how one defines professional development. Institutional culture clashes are particularly obvious between the P-12 and higher education worlds, especially as PDSs are formed. Classroom teachers are directly involved with their students most of the day. University faculty spend their days differently, with less time interacting with students and more time involved in committee work and scholarship that contributes to their understanding of specific academic disciplines. Their daily pressures are different, creating a different set of expectations for themselves and others. UBAs must recognize institutional differences and help university faculty work within and around P-12 teachers' operational habits (Hovda, 1999; Ledoux \& McHenry, 2008; Wepner, 2011; Wepner et al., 2012).

Conflicting expectations. Assumptions often are made that both the university faculty and school-based faculty want the same thing, but that is often not the case. For example, when university faculty go to a school to work with children, they might expect that the classroom teachers will work alongside them to learn about a specific instructional methodology and assist students with specific tasks. Classroom teachers, on the other hand, might see this as an opportunity to catch up on paperwork. UBAs need to help faculty to be more explicit about what is desired within the context of the learning situation (Ledoux \& McHenry, 2008; Stier, 2013; Wepner, 2011).

Communication. A linear organizational structure is supplemented with a cross-institutional system with many more voices in decision-making. UBAs need to be aware of this change in the way communication occurs so that they can do their best to anticipate and stop potential problems (Wepner et al., 2012).

One-way flow of activities from university to P-12 schools. A major concern from P-12 partners is a oneway flow of activities from the university to classrooms with little reason for teachers to take ownership of a project or to consider using the activities that have been developed by others not directly involved with the curriculum (Tomanek, 2005). A PDS is not sustained because there usually is a mismatch between the professional practices of the university faculty and the P-12 teachers, and time has not been devoted to developing a culture of professional learning and improvement. UBAs need to be acutely aware of how to develop projects and programs that come from the teachers (Wepner, 2011) because co-leadership between teachers and university faculty eliminate barriers to success (Mebane, 2000).

\section{UBAs'Leadership with Partnerships}

Minimal research exists on the importance of UBAs in forming, implementing, and sustaining PDSs so that their schools and colleges can benefit from such relationships (Breault, 2014; Stroble \& Luka, 2011; Trachtman \& Levine, 1997). Yet, UBAs are critical for the existence of partnerships. 
UBAs must be knowledgeable about the potential challenges of forming PDSs and skillful in convincing faculty to get involved in ways that are mutually beneficial. UBAs need to help faculty appreciate the value of collaboration within different institutional contexts. UBAs also need to communicate to their faculty ways in which they are placing a premium on such work for reappointment, tenure, and promotion decisions (Wepner, 2011).

UBAs, as the persons who cultivate the partnerships, need to do the following: 1) make sure the institution is ready to partner; 2) make contact with the right persons; 3) prepare before approaching a potential partner; 4) develop relationships; 5) ensure that all partners stay apprised of their responsibilities; 6) create an advisory board or leadership committee; 7) delegate; 8) provide encouragement and recognition; 9) support and participate in ceremonial duties; 10) acquire and allocate resources; 11) monitor the partnership's progress; and 12) keep the concept alive for others (Wepner, 2011).

UBAs need to have the ability to recognize the impact of their actions, and adjust accordingly; in other words, reflect about their leadership qualities. UBAs also need to have a psychological mindset for partnership work. They need to be willing to change their usual work patterns, if partnerships are a new responsibility, so that they have time and energy to cultivate partners. They need to determine ways to balance individual, institutional, community, and societal needs with their own needs (Hovda, 1999; Wepner et al., 2008).

\section{Methods}

\section{Description of Study}

The purpose of this study is to describe who UBAs are (e.g., Director of Field Placement, Director of Outreach and Partnerships, Department Chairperson, Faculty, Assistant Deans, Deans), their roles and responsibilities at their institutions, and their perspectives on the challenges of serving as UBAs. The survey questions were developed as an initial start to understand who UBAs are in relation to PDSs.

\section{Pilot Study}

Prior to the actual study, a pilot with five UBAs was conducted to determine the feasibility of engaging UBAs to respond to an established set of questions.

UBAs were surveyed, either through email or by telephone, about their roles at the university, their responsibilities in relation to PDS work, the percentage of time spent on the PDSs, and their perspectives on PDS work. To give the UBAs flexibility with two modes of responding-either by email or telephonerecordings and transcripts were not used. The Institutional Review Board (IRB) from where this study took place approved this methodology. Findings from the pilot indicated that UBAs' roles range from mid-level administrators to faculty chairpersons. They spend $25-100 \%$ of their time on PDS work. They identified three major challenges that affect their university's involvement and their oversight of PDSstransience of leadership, time, and money. They encouraged a continuation of interviews with other UBAs because of the lack of research in this area. Additionally, they reported that responding to the survey was manageable in relation to the time it took to respond and the number of items the survey included. 
The questions elicited information about UBAs' roles and responsibilities. The one open- ended question related to challenges prompted in-depth responses. Thus, the research questions for the pilot were used in this current study.

\section{Research Protocol}

Seventy-three UBAs from a variety of institutions were invited to be interviewed. The list of potential interviewees came from presenter lists from the 2014 and 2015 annual conference of the National Association of Professional Development Schools (NAPDS). The lists were alphabetized so that they could be split in half, A through $L$ and $M$ through $Z$, for the two graduate assistants who reached out to the potential interviewees.

The graduate assistants sent a scripted email to potential interviewees that introduced themselves and their role at the university, explained the purpose of the research, and requested participation with nine semi-structured interview questions, as listed in Figure 1, through email or telephone because of their role in managing their university's partnership work. The graduate assistants explained that it would take approximately 30 minutes of their time and that their responses would be kept confidential.

1. What are your responsibilities as the overseer of PDSs?

2. Is the PDS work you're involved in considered administrative work or faculty work?

3. About what percentage of your work time do you spend on PDSs?

4. How many PDSs does your university have partnerships with?

5. How long has your university been doing partnerships work?

6. What other administrators or faculty from your university are involved in PDSs?

7. How many days a week are university faculty/administrators in the schools?

8. Are the faculty involved in PDS work considered tenure-track or clinical?

9. What is the greatest challenge of your PDS work?

Figure 1. Questions for interviews of UBAs.

The graduate assistants emailed the questions to those participants who wanted to respond in writing and scheduled telephone interviews with those who preferred to respond verbally. The graduate assistants took notes for all telephone interviews. Notes from the email responses and telephone interviews were analyzed and coded for emergent themes and patterns (Corbin \& Strauss, 2007). Additionally, general demographic information about the respondents' actual positions, location of their colleges or universities by region, size and type of college or university by Carnegie Classification was gathered.

\section{Findings}

\section{Description of UBAs' Institutions of Higher Education}

A total of 24 UBAs, 33\%, completed the interview process. Thirty-six of the 73 UBAs invited to participate in the study responded, yielding a $49 \%$ return rate. Of the 36 respondents, eight had suspended or no longer partnered with PDSs and four respondents reported that they actually were not 
the UBAs. The 24 remaining UBA respondents represented a spectrum of geographical locations, institutional sizes, and Carnegie classifications.

Geographically, four regions of the United States are represented by the UBAs' Institutions for Higher Education (IHE). The majority of the IHEs, eight, are located in the South, with seven in the Northeast, four in the Midwest, and five in the West. The majority of the respondents (12) represented large IHEs, 9 respondents were from medium size institutions, and one (1) from a small IHE.

The majority of the UBAs came from public master's colleges and universities with large programs. Seven of the IHEs are private and 17 are public. The type of institutions fall into three Carnegie classifications: master's colleges and universities (13), doctoral universities (10), and baccalaureate colleges (1). Nine of the master's colleges and universities are considered to be large (at least 10,000 degree seeking students) programs, three are considered to be medium (3,000-9,999 degree seeking students) and 1 is considered to be small (1,000 to 2,999 students). Doctoral universities, classified by Carnegie for their research activity, indicated that five of the doctoral universities have the highest research activity, three have higher, and two have moderate research activity. Table 1 displays the demographic data of the UBA respondents.

Table 1

Demographic Information of Respondents

\begin{tabular}{lr}
\hline $\mathrm{N}=24$ & $\mathrm{n}$ \\
\hline Regions & \\
Northwest & 7 \\
South & 8 \\
Midwest & 4 \\
West & 5 \\
Size & \\
Small & 3 \\
Medium & 9 \\
Large & 12 \\
Carnegie Classification & \\
Private & 7 \\
Public & 17 \\
Doctoral Universities & \\
$\quad$ Moderate & \\
$\quad$ Higher Research & 2 \\
$\quad$ Highest Research & 3 \\
Master's Colleges \& Universities & \\
$\quad$ Small & \\
$\quad$ Medium & 1 \\
$\quad$ Large & 3 \\
Baccalaureate Colleges & 9 \\
$\quad$ Arts \& Sciences & \\
\hline$\quad$
\end{tabular}


The number of PDSs at the UBAs' IHEs ranged from 1 to 148, with one institution having international PDSs (Question \#4). The majority of the IHEs, 46\%, had between one and ten PDSs. The second largest range of number of PDSs, 21\%, was between 11 and 19 PDSs.

The majority of the UBAs reported that their IHEs have been doing PDS work for over ten years (Question \#5). Almost half, 46\%, of the IHEs had been doing PDS work for 11 to 20 years. Approximately one quarter, $29 \%$ and $25 \%$ respectively, had been doing PDS work for less than ten years and over 20 years.

\section{Roles of UBAs}

When asked whether PDS work was considered administrative work or faculty work (Question \#2), $50 \%$ (12) of the UBAs responded that it was considered faculty work. Eight respondents considered it to be administrative work and four considered it both administrative and faculty work. Those who considered it administrative work held positions such as director for field placement or director for community outreach and partnerships. Those who considered it faculty work were often chairpersons, and had titles reflecting their coordinator responsibilities.

There was a wide range of responses to the question, "About what percentage of your work time do you spend on PDSs?" (Question \#3). The percentage ranged from 10 to $100 \%$, with the majority of the UBAs spending $50 \%$ or less of their time on PDS work. Respondents shared that the time spent "varies based on the time of year"; "25-50\% in spring (applications due) ... Few hours rest of year"; "25\% officially, $40 \%$ reality"; "difficult to answer, integrated into many parts of work"; and "not enough-have to wear another hat."

\section{PDS Responsibilities}

Some respondents reported that part of their responsibilities were related to a professorial role, such as teaching, presenting and facilitating workshops, conducting research and inquiry, training, and teaching courses. However, an analysis of the responses to the question, "What are your responsibilities as the overseer of PDSs?" (Question \#1) revealed three major administrative responsibilities: personnel, programs, and documents. Figure 2 includes the type of activities for each administrative responsibility.

Personnel. UBAs mentioned as a major responsibility their personal interactions with four stakeholder groups: university, local schools, community, and teacher candidates. The individual representatives from each stakeholder group varied. University stakeholders included tenure-track faculty, clinical faculty, adjuncts, PDS liaisons, university program directors and coordinators, deans, university presidents, presidential cabinets, and Board of Trustees (Question \#6). The UBAs explained that they were responsible for hiring or securing mentors, cooperating teachers, teachers in residence, and university colleagues to work in and with PDSs. UBAs interacted with faculty, principals, and staff in local schools and district level administrators and staff in local districts. They also interacted with community stakeholders such as parents and the local school boards.

UBAs' interactions with teacher candidates varied according to the UBA's responsibilities with PDS oversight. The teacher candidates were graduate or undergraduate students seeking teaching credentials at the elementary or secondary level, and represented a variety of content area specialties. Overall, and as 
one respondent stated about interactions with personnel, the role of the UBA is, "to oversee X's network of schools and to support the people involved in it."

\begin{tabular}{|l|l|l|}
\hline \multicolumn{1}{|c|}{ Personnel } & \multicolumn{1}{|c|}{ Programs } & \multicolumn{1}{c|}{ Documents } \\
\hline Collaborate with stakeholders & Develop, design and maintain & Maintain documents - \\
Support participants & programs, partnerships & agreements, MOUs, vouchers, \\
Coordinate placements, & Recommend direction of PDS & evaluations, award applications \\
leaders, school-university, & Renew existing and create new & Collect data \\
cohorts & programs & Write newsletter, annual \\
Work with faculty, public, and & Recruit new schools, sites & reports \\
faculty liaisons & Plan, facilitate, and report \\
Secure mentor teachers & ldentify needs & committee meetings \\
Monitor candidates' progress & & Maintain alignment with \\
Maintain relationships & standards, rubrics \\
Resolve disputes & \\
\hline
\end{tabular}

Figure 2. Administrative responsibilities as overseer of PDSs

UBAs reported that their university faculty/administrators spend about two to five days per week in the PDSs (Question \#7). The time spent in the schools seemed to relate to programing and structure as evidenced by the following responses: "University supervisors 8 times/semester," "... based on if student teachers and/or courses taught at site," and "once every two weeks for each school that has a candidate." UBAs responded that $89 \%$ of the faculty who work at the PDSs were a combination of tenure-track and clinical, and $11 \%$ were clinical only (Question \#8).

Programs. UBAs noted as a major administrative responsibility the maintenance of existing PDS programs and the creation of new programs. To maintain existing programs, UBAs had to provide professional development for teachers and staff, communicate with partners, provide program improvements and renewal, and plan retreats. To create new programs, UBAs reported that they identified needs, explored and organized new opportunities, oversaw program design, and recruited new PDS sites.

Documents. UBAs noted that they had to manage and create documents as a major responsibility of their PDS work. Documents included: agreements and vouchers, Memoranda of Understanding (MOUs), budgets, committee minutes, annual reports, newsletters, applications, data reports, and standards alignment documents.

\section{UBAs'Challenges}

Three themes emerged from the question about the greatest challenge of PDS work (Question \#9): time, sustainability, and resources/support. One respondent summed it up, "There are many ... time, money, willing faculty, willing partners, competing philosophies ... All make the work exciting and interesting!" Figure 3 lists the challenges that UBAs mentioned. 


\begin{tabular}{|l|l|l|}
\hline \multicolumn{1}{|c|}{ Time } & \multicolumn{1}{|c|}{ Sustainability } & \multicolumn{1}{c|}{ Resources/Support } \\
\hline $\begin{array}{l}\text { Motivating faculty, old and } \\
\text { new, to stay involved, } \\
\text { considering their workloads } \\
\text { outside the PDS } \\
\text { Finding the time to publish }\end{array}$ & $\begin{array}{l}\text { Maintaining the relationship as } \\
\text { stakeholders change } \\
\text { Changing administrations } \\
\text { Changing personnel at both the } \\
\text { university and school levels } \\
\text { Making mentors feel connected } \\
\text { to the process }\end{array}$ & $\begin{array}{l}\text { Accommodating the various } \\
\text { disciplines and levels of } \\
\text { teaching } \\
\text { Finding funding } \\
\text { Finding relevant research data } \\
\text { about PDSs } \\
\text { Finding enough students to } \\
\text { place } \\
\text { Finding enough school district } \\
\text { administrators to oversee PDSs } \\
\text { and resolve challenges } \\
\text { Being able to place all students } \\
\text { in exemplary schools }\end{array}$ \\
& &
\end{tabular}

Figure 3. Examples of challenges.

Time. The myriad of responsibilities at both the university and PDS levels required time. The challenge of time is exemplified by this response, "Finding time to sleep! This is a much longer question and one I don't have the time to answer right now. A short answer would not do justice to the complexity of the issues. Sorry."

Time was spent on many administrative responsibilities. UBAs reported that they used their time for monitoring, public relations, supporting, planning, and coordinating the various components of the PDS. One respondent elaborated, as follows:

Perhaps the time involved with coordination of a program that has approximately 300 preservice teacher candidates enrolled each year can be considered challenging. I make a commitment to always answer all of the e-mails received from our pre-service teacher candidates each day. This can take a few hours, especially in that I also teach a few courses/seminars each semester. Coordination of various components of the program (i.e., monitoring the budget, making placements, sending electronic and snail mail correspondence between partners and preservice teacher candidates) continues to be a daily need of my attention. I also serve as a liaison for 4 of our partnering PDS locations. This keeps me involved with the local school activity as well as modeling the partnership between/among our PDSs and our pre-service teacher candidates.

Another UBA summed up PDS work as "a challenge and a benefit - the work is never done."

Sustainability. "Constant change in personnel at both the university and school levels" was often cited as the greatest challenge. Sustainability was viewed as difficult when there were "changes in administration ... having a true systemic impact." A change in administration can alter the direction of the partnership because of philosophical differences between the old and new administration, as reflected by this UBA's comment "... a high rate of turnover and the current administrators at both the school and university level wanted to go in a different direction than the formal PDS system they are in."

One respondent offered an explanation for this challenge. "There have been numerous changes for teachers over the past few years. Examples include PARCC test implementation, accountability laws and 
the shift to edTPA. As a result, finding teachers who are willing to become mentor teachers amidst this instability has become increasingly more difficult."

Resources/Support. Having sufficient financial resources contributed to UBAs' ability to sustain PDSs. Some PDSs garnered funds from the university and the school district. Others used PDS activities, such as PDS conferences, as additional revenue sources. As one UBA stated, "Budget constraints make it difficult to give back to schools, particularly cooperating teachers." Even when there was funding, the appropriate use of funding could be a challenge, as one respondent noted with "ensuring schools are using funding to do PDS work." Another UBA found that some schools ". . . were concerned mostly about receiving money."

As one UBA stated, "PDSs are ever-evolving so keeping up with the system as time evolves is paramount." Another respondent summed up the challenge for UBAs by stating that the need is to create a PDS system that is "equitable without being identical."

\section{Discussion and Implications}

University-based leadership of professional development schools is essential for promoting a shared commitment with school-based partners (Byrd \& McIntyre, 2011; Duffield \& Cates, 2008). Universitybased administrators, or UBAs, need to be better understood for their contribution to promoting schooluniversity relationships (Stroble \& Luka, 2011). This study attempted to identify UBAs at different universities across the United States to begin to understand their perspectives on their roles and responsibilities in relation to their universities' PDS history and structure.

The findings revealed significant variation in UBAs' roles and responsibilities. There is no standardized leadership title, set of responsibilities or qualifications, or structure for the oversight of PDS activities and networks. Most UBAs who responded to the interview questions revealed that they are primarily faculty with coordinator responsibilities. They spend $10-50 \%$ of their time overseeing personnel and programs related to PDS sustainability and growth.

UBAs also must attend to the many different types of documents related to PDS work. Similar to findings from the pilot study, time and resources/support are major challenges for sustaining PDSs. Although coming from institutions of various sizes and complexities with different histories and different levels of commitment to PDS work, the UBAs nevertheless saw themselves as pivotal persons for working with and connecting stakeholders, sustaining relationships, and maintaining and promoting PDS growth in the face of challenges.

Since the majority of the respondents considered PDS oversight to be faculty work, institutions of higher education should be thoughtful about whom they select of be their UBAs. UBAs need to have the knowledge, skills, and dispositions to negotiate two cultures: their own university and their PDSs. They need to understand and navigate the challenges of cross-institutional partnerships as diplomatically as possible and work assiduously to keep all stakeholders committed to the partnership.

UBAs also need to understand how to develop and execute partnership agreements, monitor budgets, work effectively with personnel, and ensure that initiatives are appropriate, functioning, and well-funded. If UBAs are not already in administrative positions (e.g., education deans, assistant deans, or field placement directors), questions that should be asked to identify appropriate UBAs include:

- What qualifications does the UBA have for PDS work? 
- How influential is the UBA with faculty to encourage them to work in PDSs and work within and around partnership challenges?

- How effective is the UBA's ability to communicate with stakeholders?

- How flexible is the UBA?

- How does the UBA manage time?

- What are the UBA's conflict resolution skills? Problem-solving skills?

- How well does the UBA attend to details and follow through on projects?

- What experience does the UBA have with fundraising or grant writing?

- In what ways do the UBA's skills set match the goals of the PDS(s)?

Additionally, institutions of higher education should make sure that there is clear alignment between UBAs' compensation in relation to the requirements for overseeing the PDSs. Does the UBA have enough time in his or her schedule to be successful? Are resources and funding in place to sustain the UBA's role?

This study's sample size limits the ability to generalize about the roles and responsibilities of UBAs. An expanded pool of respondents and a modified interview format would contribute to an in depth understanding of the roles, responsibilities, and challenges of UBAs. An interview format with additional open-ended questions could help to determine a) optimum roles and responsibilities of UBAs, b) necessary characteristics of UBAs, and c) ways to secure support from university administrators for UBA and PDS support. Such research would contribute to a better understanding of the importance of UBAs to support PDSs.

A possible resource for this additional research is the National Association of Professional Development Schools (NAPDS). This organization can be used to tap into its membership to identify UBAs who could participate in the interviews. This additional research could contribute to a comprehensive profile of UBAs as leaders who support and sustain PDSs. This profile could be used to establish guidelines and eventually standards for the optimum roles and responsibilities of UBAs to help PDSs to continue to endure.

\section{Declaration of Conflicting Interests}

The authors declared no potential conflicts of interest with respect to the research, authorship, and/or publication of this article.

\section{Funding}

The authors received no financial support for this research.

\section{References}

Bowen, G. (1995, August). The role of the principal in the professional development school. Paper presented at the Annual Meeting of the National Council of Professors of Educational Administration, Williamsburg, VA. Retrieved from http://files.eric.ed.gov/fulltext/ED401639.pdf

Bowen, G., \& Adkinson, J. (1996). Institutionalizing professional development schools: Supporting the principal. (ERIC Document Reproduction Service No. ED 409623). Retrieved from http://eric.ed.gov/?q=ED4096238xid=ED409623

Breault, R. (2014). Power and perspective: The discourse of professional development school. AsiaPacific Journal of Teacher Education, 42(1), 22-35. doi: 10.1080/1359866X.2013869547 
Byrd, D. M., \& McIntryre, D. J. (2011). Types of partnerships. In S. B. Wepner \& D. Hopkins, (Eds), Collaborative leadership in action: Partnering for success in schools (pp. 27-48). New York, NY: Teachers College Press.

Castle, S., Rockwood, K. D., \& Tortora, M. (2008). Tracking professional development and student learning in a professional development school partnership. School-University Partnerships, 2(1), 47-60.

Corbin, J., \& Strauss, A. (2007). Basics of qualitative research: Techniques and procedures for developing grounded theory. Thousand Oaks, CA: Sage.

Duffield, J. A. \& Cates, W. M. (2008). Establishing and maintaining professional development schools: A delphi study. School-University Partnerships., 2(2), 27-50.

Epstein, J. L. \& Sanders, M. G. (2006). Prospects for change: Preparing educators for school, family, and community partnerships. Peabody Journal of Education, 81(2), 82-120. doi: 10.1207/s15327930pje8102_5

Ferrara, J., \& Gómez, D. W. (2014). Broadening the scope of PDS liaisons' roles in community schools. School-University Partnerships, 7(1), 110-117.

Field, S. S. (2008). How highly effective professional development school principals utilize researchbased leadership practices to lead the school-university partnership (Doctoral dissertation). Retrieved from ProQuest Dissertations and Theses. (Accession Order No. AAT 3312857)

Gilles, C., Wilson, J., \& Elias, M. (2009). School-university partnership: Perceptions of the teachers. School-University Partnerships: The Journal of the National Association for Professional Development Schools, 3(1), 100-112.

Hamel, F. L., \& Ryken, A. E. (2010). Rehearsing professional roles in community: Teacher identity development in a school-university partnership. Teacher Development, 14(3), 335-350. doi: $10.1080 / 13664530.2010 .504015$

Hovda, R. A. (1999). Working on a public school calendar: Personal reflections on the changing role of university faculty member in a professional development school. Peabody Journal of Education, 74(3/4), 85-94. doi: 10.1080/0161956x.1999.9695374

Ledoux, M. W., \& McHenry, N. (2008). Pitfalls of school-university partnerships. The Clearing House, 81(4), 155-160. doi: 10.3200/tchs.81.4.155-160

McBee, R. H., \& Moss, J. (2002). PDS partnerships come of age. Educational Leadership, 59(6), 6164.

Mebane, D. J. (2000). Responses of first-year participants in a middle school professional development schools partnerships. The Journal of Educational Research, 93(5), 287-293. doi: 10.1080/00220670009598720

Moreno, N. (2005, Spring). Science education partnerships. Being realistic about meeting expectations. Cell Biology Education, 4(1), 30-32. doi: 10.1187/cbe.04-11-0050

Strier, R. (2014). Fields of paradox: University-community partnerships. Higher Education, 68(2), 155-165. doi: 10.1007/s10734-013-9698-5

Stroble, B., \& Luka, H. (2011). It's my life now: The impact of professional development school partnerships on university and school administrators. Peabody Journal of Education, 74(3/4), 123135. doi: $10.1207 / \mathrm{s} 15327930$ pje7403\&4_10

Teitel, L. (1996). Getting down to cases: Tackling the "undiscussable" issues of professional development school partnerships. Contemporary Education, 67(4), 200-205.

Teitel, L. (1997). Changing teacher education through professional development school partnerships: A five year follow-up study. Teachers College Record, 99(2), 311-334. 
Teitel, L. (1998). Governance: Developing professional development school governance structures. Washington, DC: American Association for Colleges of Teacher Education Publications.

Teitel, L. (1999). Looking toward the future by understanding the past: The historical context of professional development schools. Peabody Journal of Education, 74(3/4), 6-20. doi: 10.1207/s15327930pje7403\&4_1

Teitel, L. (2003). The professional development school handbook: Starting, sustaining, and assessing partnerships that improve student learning. Thousand Oaks, CA: Corwin Press.

Tilford, K. (2010). A phenomenological study of professional development schools: How principals make sense of their role. School-University Partnerships, 4(2), 60-73.

Tomanek, D. (2005, Spring). Building successful partnerships between P-12 and universities. Cell Biology Education, 4(1), 28-29. doi: 10.1187/cbe.04-11-0051

Trachtman, R., \& Levine, M. (1997). Reinventing leadership in professional development schools. In R. Trachtman \& M. Levine (Eds.), Making professional development schools work: Politics, practice, and policy (pp. 76-87). New York, NY: Teachers College Press.

Walker, D. A., Sorensen, C. K., Smaldino, S. E., \& Downey, P. M. (2008). A model for a professional development school intervention: Real findings. School-University Partnerships, 2(1), 6-26.

Walker, C., Zeek, C. K., Foote, M. M., \& Naizer, G. (2008). Re-creating teacher education through long-term partnerships. In I. Guadarrama, J. M. Ramsey, \& J. L. Nath (Eds.), University and school connections: Research studies in professional development schools (pp. 203-220). Charlotte, NC: Information Age Publishing, Inc.

Wepner, S. B. (2011). Defining collaborative leadership. In S. B. Wepner \& D. Hopkins (Eds.). Collaborative leadership in action: Partnering for success in schools (pp. 121-144). New York, NY: Teachers College Press.

Wepner, S. B. (2014a). The role of leadership in the PDS. In J. Ferrara (Au.), Professional development schools: Creative solutions for educators (pp. 121-128). Lanham, MD: Rowman \& Littlefield.

Wepner, S. B. (2014b). Developing partnerships through collaboration to promote professional development. In S. Kragler, L. Martin, K. L. Bauserman, \& D. Quatroche (Eds.), The handbook of professional development, PK-12: Successful models and practice (pp. 339-358). New York, NY: Guilford.

Wepner, S. B., Bettica, A., Gangi, J., Reilly, M. A., \& Klemm, T. (2008). Using a cross-curricular learning experience to promote student engagement through a school-college collaboration. Excelsior, 3(1), 27-45.

Wepner, S. B., Ferrara, J., Rainville, K. N., Gómez, D.W., Lang, D. E., \& Bigaouette, L. (2012). Changing suburbs, changing students: Helping school leaders face the challenges. Thousand Oaks, CA: Corwin Press. 